Brief Report

\title{
Dronar-Geoforensic Search Sonar from a Drone
}

\author{
Alastair Ruffell *, Amy Lally (i) and Benjamin Rocke (1) \\ School of the Natural Built Environment, Queen's University, Belfast BT7 1NN, UK; alally01@qub.ac.uk (A.L.); \\ brocke01@qub.ac.uk (B.R.) \\ * Correspondence: a.ruffell@qub.ac.uk
}

check for

updates

Citation: Ruffell, A.; Lally, A.; Rocke, B. Dronar-Geoforensic Search Sonar from a Drone. Forensic. Sci. 2021, 1, 202-212. https://doi.org/10.3390/ forensicsci1030018

Academic Editor: Aurea Carvalho

Received: 30 September 2021

Accepted: 20 November 2021

Published: 25 November 2021

Publisher's Note: MDPI stays neutral with regard to jurisdictional claims in published maps and institutional affiliations.

Copyright: (c) 2021 by the authors. Licensee MDPI, Basel, Switzerland. This article is an open access article distributed under the terms and conditions of the Creative Commons Attribution (CC BY) license (https:// creativecommons.org/licenses/by/ $4.0 /)$.

\begin{abstract}
Lightweight sonar devices may be tethered to an unmanned aerial vehicle or drone and quickly deployed over water for real-time imaging in 2D and the on site creation of geolocated, interactive bathymetric maps without the need for a boat. We show how such data is useful in the preliminary stages of water searches, by providing geophysicists, hydrologists and divers with spatial depth information, the distribution of dive and equipment hazards such as entanglement objects (weed, discarded items) and sediment types. One bathymetry case study location is described in detail, with a further two summarized to demonstrate reconnaissance surveys. Limitations of drone-based sonar surveys are outlined, including dense water weed cover; limits on flight times and adverse weather conditions.
\end{abstract}

Keywords: UAV; sonar; water-based search; Geoforensics; bathymetry

\section{Background: Why Might Remote Bathymetry Be Needed?}

The search for buried or sunken human remains is best achieved by gathering as much background information as possible, prior to the deployment of search personnel. In the terrestrial environment, this comprises a desktop study, followed by a walk over assessment of feasibility, including ground topography [1]. For aqueous environments, publicly available historical data may be available, but knowledge of bathymetry and sediment conditions is likely to be incomplete, due to inaccessibility and constantly changing environments, such as water depth and siltation. Thus, to plan a search, rapid and reliable water bathymetry is essential: this work explores whether lightweight sonar (sound navigation and ranging) devices, tethered to unmanned aerial vehicles (UAV's, known commercially as drones (used hereon)) can achieve this goal: we abbreviate this combined use as "Dronar" for ease of communication.

Active sonar is a widely used imaging system in water surveys [2,3] and specifically in the forensic search for human remains in water [4]: be it single beam echo sounding [5]; multibeam for mapping waterbed surfaces (op. cit); or sidescan [6]. All active sonar systems rely on the generation, propagation and reflection of acoustic waves from a transmitter to receiver, commonly housed in the same device. Data outputs may comprise twodimensional (vertical) depth profiles; two-dimensional (horizontal) depth to water base maps and three dimensional datasets [7], with the most common being sidescan imaging for the location of sunken objects. Intensifying an acoustic pulse can be achieved using a CHIRP (compressed high intensity radar pulse) system, which improves horizontal resolution at wider operating ranges: this may allow the visual differentiation of closely spaced targets and suppression of noise [8]. The use of sidescan sonar, divers, as well as more specialist underwater cameras (endoscopes), CHIRPs, water-penetrating radar, water trained scent dogs and geochemical analysis should be based on a desktop study of available information (geology, soils/catchments, hydrology, past water use). However, water bodies are dynamic and may comprise small (e.g., $~ 1 \mathrm{~km}$ diameter) covert forensic search locations that usually do not have up to date information at the detail required for surveys that include minor waterways [9], requiring background information such as 
bathymetry to be gathered. Acquiring such contemporary and reliable information has previously needed the deployment of boats in sometimes hard to access environments; thus, most surveyors perform what is bad practice, and deploy equipment and personnel "blind", with no prior knowledge. This approach can be successful if left down to luck, but forces the investigator to gather what should have been background data as the work progresses. In the author's experience, however, if a rapid and reliable means of obtaining such background data is available, it is worth considering. Likewise, sonar and CHIRP may not be successful where excessive weed, gas bubbles and rocky substrates are present, requiring assessment prior to boat deployment. We test the ability to take this background data by using a drone mounted sonar and CHIRP system, deployed in a similar manner to [10], but concentrating on mapping the entire bathymetry of lacustrine and fluvial locations, as in Giambastiani et al. [11].

\section{Equipment and Methods}

Bandini et al. [10] completed novel research by attaching a commercially available fishing sonar (Deeper Smart Sonar Pro+), via a winch mechanism, to a DJI Spreading Wings S9000 hexacopter. They used this approach to remotely measure the water depths of a Danish lake and two rivers. This work follows Bandini et al. [10] with the following variations:

(1) a Deeper Smart Sonar Pro+ and Deeper CHIRP+ 2 were utilized. The capabilities of both devices are presented in Table 1. Each device contains a WiFi module which connects to a smart device to record real-time data;

(2) the sonar devices were suspended on a static line (no winch) from three different drones: a DJI Mavic Pro, a DJI Phantom and a DJI Inspire 2;

(3) the Fish Deeper app, containing in built bathymetric mapping software, was utilized for on-site water depth evaluation;

(4) we are demonstrating a quickly deployed and low cost data acquisition technique that is thorough enough to evaluate the feasibility of an underwater forensic search, if not complete it. Raw data, containing GPS points with corresponding water depth measurements were imported into an ArcGIS Pro to create detailed bathymetric maps which aid in the desktop study portion of the geoforensic search strategy (GSS) of Donnelly \& Harrison [1]. The raw data were downloaded as .csv files from the Deeper Data Manager site 'LakeBook' found at https:/ / maps.fishdeeper.com (last accessed 20 November 2021).

Table 1. The capabilities of both Deeper products utilized in this work.

\begin{tabular}{ccc}
\hline & Deeper Smart Sonar Pro+ & Deeper CHIRP+ 2 \\
\hline Wide angle sonar beam frequency & $55^{\circ}-90 \mathrm{kHz}$ & $47^{\circ}-100 \mathrm{kHz}$ \\
\hline Narrow angle sonar beam frequencies & $15^{\circ}-290 \mathrm{kHz}$ & $\begin{array}{c}20^{\circ}-240 \mathrm{kHz} \\
7^{\circ}-675 \mathrm{kHz}\end{array}$ \\
\hline Weight & $92 \mathrm{~g}$ & $100 \mathrm{~g}$ \\
\hline Built in GPS & Yes & Yes \\
\hline Minimum scanning depth & $50 \mathrm{~cm}$ & $15 \mathrm{~cm}$ \\
\hline Maximum scanning depth & $80 \mathrm{~m}$ & $100 \mathrm{~m}$ \\
\hline WiFi range & $100 \mathrm{~m}$ & $120 \mathrm{~m}$ \\
\hline Target separation & $2.5 \mathrm{~cm}$ & $1 \mathrm{~cm}$ \\
\hline Record water temperature & Yes & Yes \\
\hline Battery Life & $6 \mathrm{~h}$ & $15 \mathrm{~h}$ \\
\hline
\end{tabular}

The rationale for the above variations to previous work include:

(1) to compare the scanning depths of both devices between both sonar devices, as the newly developed Deeper CHIRP +2 is advertised as having shallow water (less 
than $50 \mathrm{~cm}$ ) and subsediment imaging capability. The accuracy of the drone derived depth measurements was tested against boat derived plumb bob measurements and water penetrating radar profiles for a number of the test sites.

(2) test flights were undertaken in low wind conditions on open water, where a winch mechanism, similar to Bandini et al. [10], can be easily installed.

(3) and (4) provide basic, yet up to date bathymetric maps and sediment type (on the latter, see Gutowski et al. [12] of a greater number of small water bodies where publicly available data is not available or accessibility is limited.

\section{Drone Sonar: Study Sites and Data Acquisition}

For this test of whether sonar from a drone may be a suitable addition to water surveys, we gathered data from three sites in Northern Ireland (UK):

Site 1 comprises a bathymetric survey of a recreational natural lake with known anthropogenic objects;

Site 2 was a targeted survey over a submerged archaeological feature in a lake in forest service land;

Site 3 was surveyed to assess water volumes in an isolated dammed lake, presumed to be relatively free of anthropogenic targets, and is included to show the problems of aquatic weed growth in a forensic engineering context.

We describe our methodology for Site 1 for simplicity as an example of a small survey environment, typical of those we are asked to survey for search authorities. Data acquisition was the same for all sites (summarized in Figure 1), comprising full safety checks of the drone, tether, sonar and weather/water conditions at a smooth launch site. Flights were nonautonomous (drone pilot controlled) to allow emergency landing, with a trial flight prior to any survey.

Site 1 is the Queen's University, Belfast Water-ski Club facility at Lough Henney (County Down, N.Ireland), with a nearby lake (Lough Aghery), where presurvey test flights (Figure 1) were undertaken. Lough Henney comprises a $0.8 \mathrm{~km}(\mathrm{E}-\mathrm{W})$ long, $0.35 \mathrm{~km}(\mathrm{~N}-\mathrm{S})$ wide, $0.16 \mathrm{~km}^{2}$, postglacial interdrumlin lake, sited on the NE-SW oriented (fault) boundary of Lower Palaeozoic metamorphosed shales and sandstones, below glacial/postglacial till and alluvium (Figure 2). Users of the lake facility provided anecdotal evidence of $6 \mathrm{~m}$ lake depths at the center and some submerged objects, such as sunken water ski ramp wires (dislodged in winter storms, Figure 3), replicating one search scenario. These depths were previously measured using a StarFish boat borne sonar. The Deeper CHIRP+ 2 was suspended from a Mavic Pro drone and flown around the perimeter of the lake, as in Figure 1. To show how data sets may be combined, the remainder of the lake was flown at a later date with the Inspire drone. Further information can be found in Supplementary Files Videos S1-S5. 

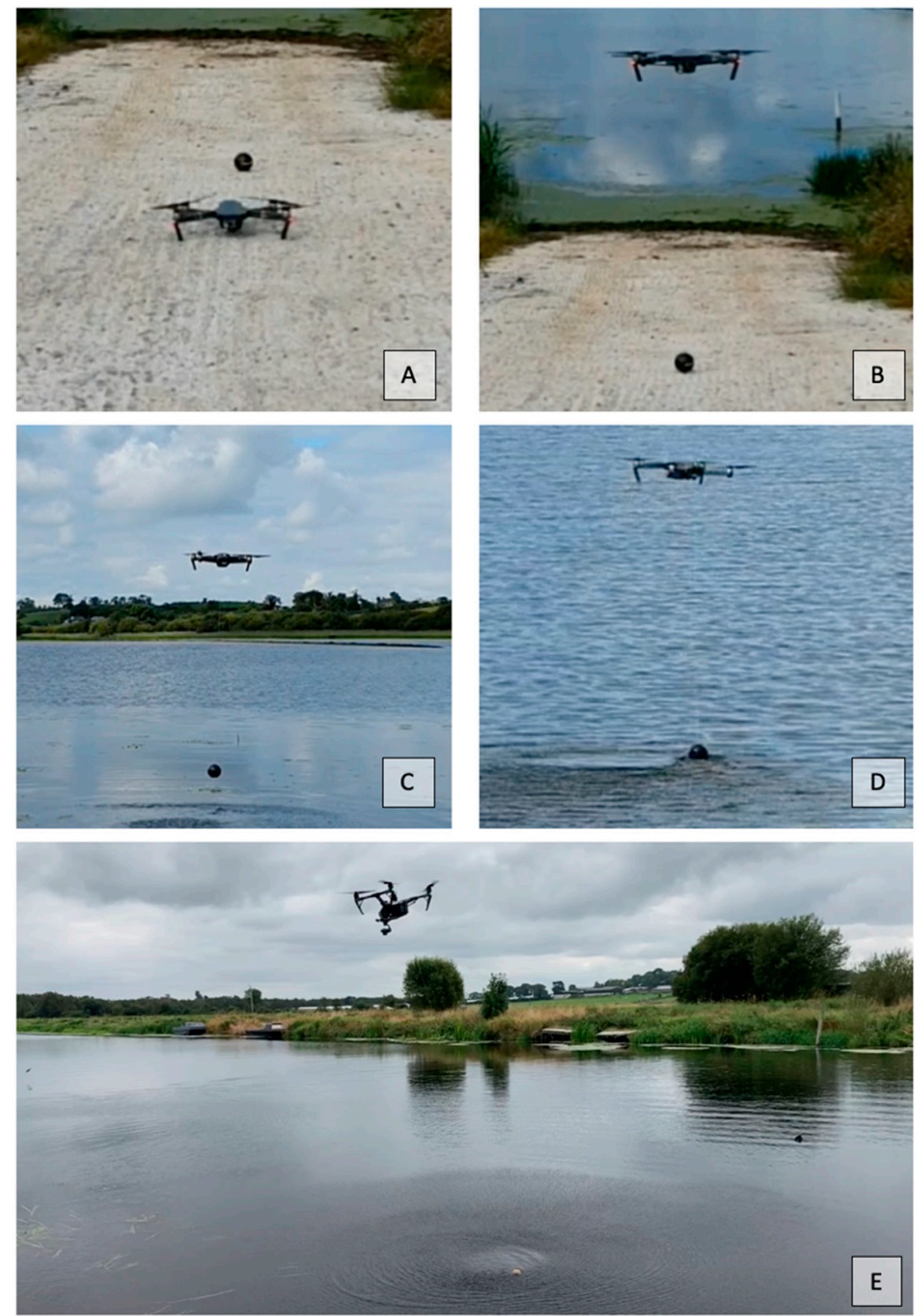

Figure 1. Test flight image stills from video (see Supplementary Files Videos S1-S5) to show the simple launch and deployment procedure. (A) Possible launch scenario. MavicPro drone with tethered Deeper Smart Sonar+ behind; (B) MavicPro drone during operator controlled take off; (C) MavicPro drone beginning deployment such that the sonar begins WiFi connection to controller and scanning; (D) MavicPro drone with sonar in scanning mode. (A-D): all at the test and detailed study locations (Figures 2 and 3). (E) DJI Inspire 2 drone with Deeper CHIRP+ 2 device, scanning a river in N. Ireland. 

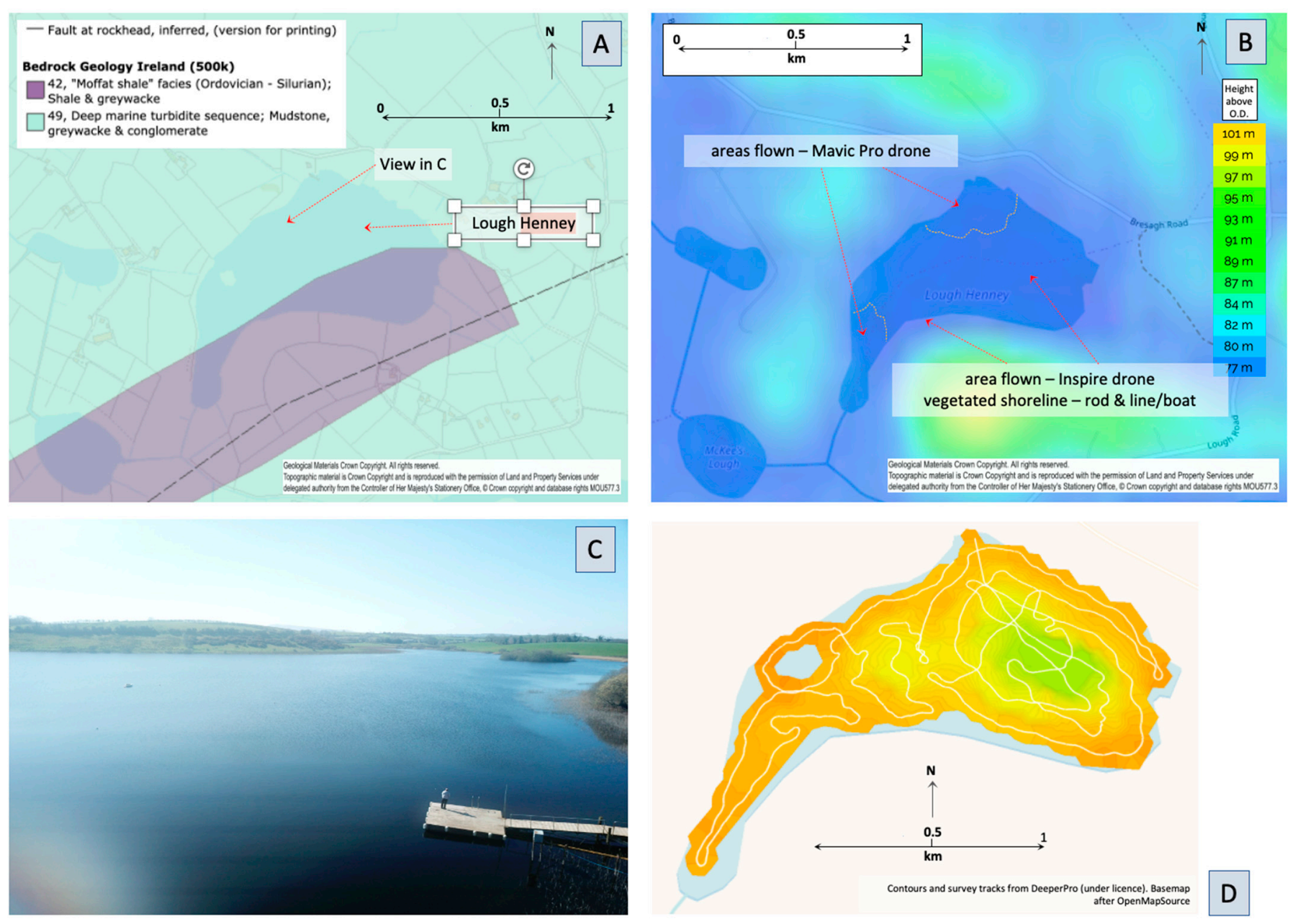

Figure 2. Background information and bathymetry on the detailed case study at Site 1. (A) Bedrock geology (note the underlying structure is oriented NW-SW, as in the elongated, southwestern portion of the lough); (B) topography of Site 1; (C) drone image at $60 \mathrm{~m}$ height of the southwestern area; (D) bathymetric map, created after $4 \mathrm{~h}$ (total) of sonar (drone, boat, shore based) surveying: suitable for same day survey planning, but can be brought into GIS for further analysis and output as contour line maps (see Supplementary Files Videos S7), as recommended by Stoelzle and Stein [13].

Furthermore, where upstanding vegetation was predicted to cause a flight hazard, these areas were completed by either the sequential lowering of the drone and sonar vertically to provide spot depth measurements, or by shallow casting the Deeper buoy using a standard fishing rod. Sites 2 and 3 were surveyed (location maps in Figures 4 and 5) in much the same way, with deeper water negating any need for any shore based data acquisition at Site 2 and very thick weed precluding any data being collected at a small portion of Site 3 (southern end, see Figure 5). 

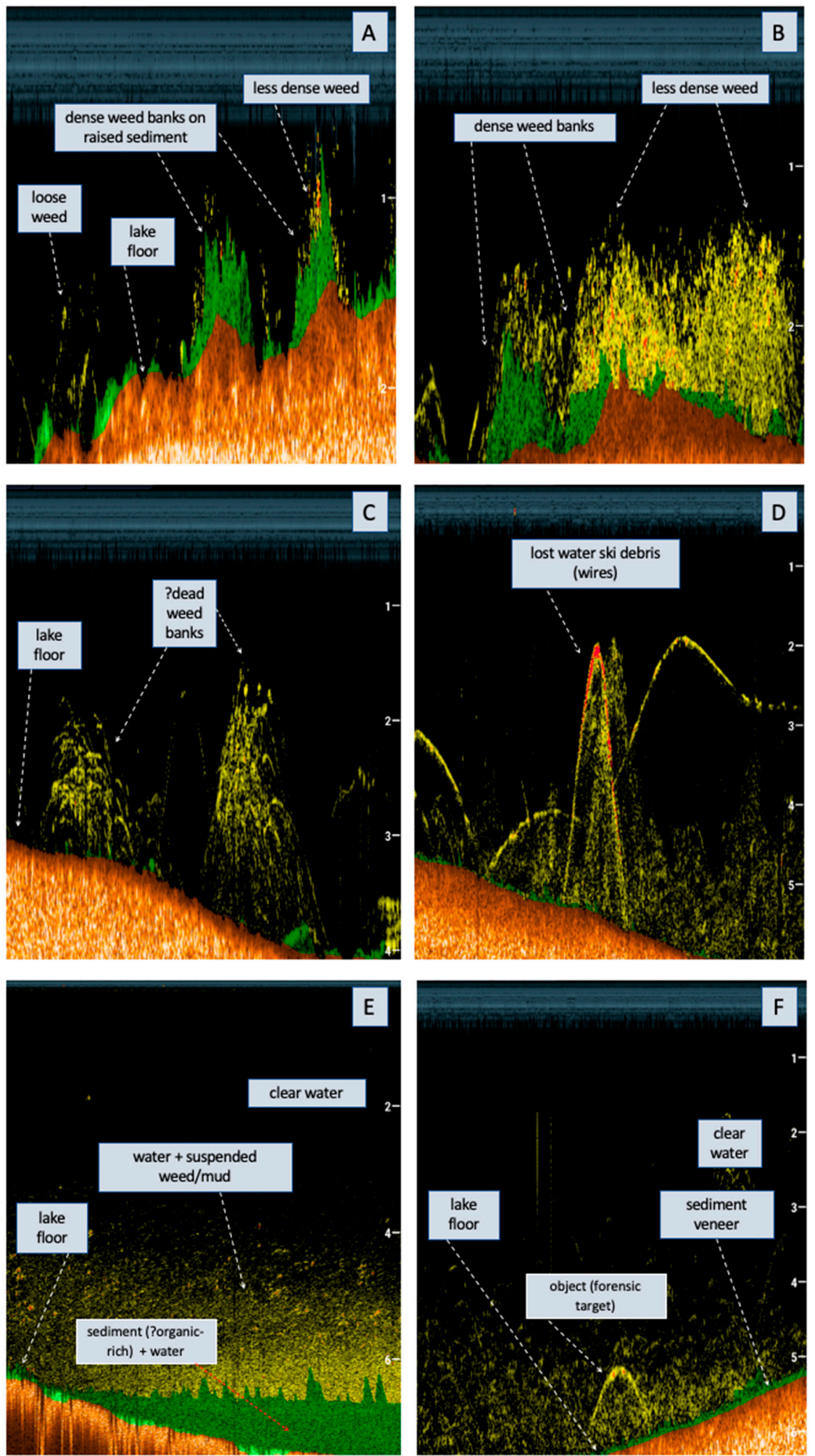

Figure 3. Examples of real time sonar (here, CHIRP) data from Site 1, acquired by drone and viewed onshore, such as assessing dive depths and hazards. (A-C) Sonar data display on FishDeeper app. Vegetation can be seen as vertical green and yellow structures, with the brown structure representing the lakebed; (D) yellow arc reflections representing sunken water ski debris; (E) yellow reflected area likely represents suspended weed or mud along the lake bottom which contrasts to reflection-free clear water above. (F) yellow arc reflection representing a submerged object (water ski debris). 


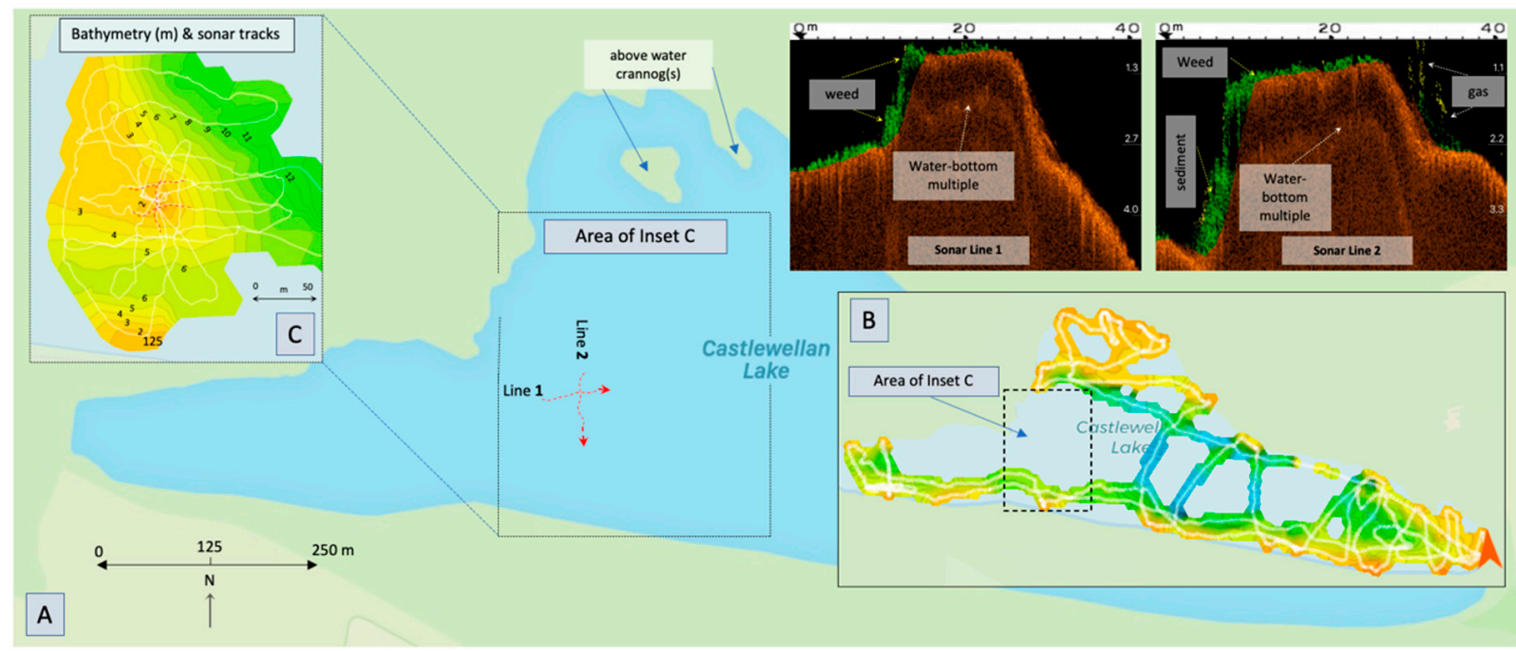

Figure 4. Site 2 data is shown where reconnaissance lines were flown by drone to narrow a boat borne sonar and water penetrating radar search for a medieval crannog (dwelling/defensive structure in water), detailed in Ruffell and King (2021) [14]. (A) Map of the lake (from AppleMaps), insets: 2D lines of crannog. (B) Reconnaissance sonar lines and depths; (C) detailed sonar bathymetry over the upstanding feature, thought to be a crannog (here, likely medieval—a lake dwelling and/or defensive structure).

\section{Initial Results}

All surveyed sites yielded bathymetry from $30 \mathrm{~cm}$ depth to over $10 \mathrm{~m}$ depth, validated by plumb-bob and water-penetrating radar (WPR), and captured target objects, some of which were confirmed by visual observation in clear water. Examples from Site 1 are shown in Figure 3 with some preliminary interpretations, such as a water surveyor may make in real time to advise search personnel, added to a water depth/volume inventory and/or to be ready for further surveys of water volume, siltation, underwater archaeology or water sampling.

Studies of water volumes, flood risk, agricultural/climate change induced siltation and forensic searches rely on knowledge of water depths and sediment/weed extent [3], such as this survey provides. A summary bathymetric map does not provide adequate detail in comparison to real time data captured on screen and, here, as an accessory file (Supplementary Files Videos S6). Figure 4 shows a bathymetric map of Site 2, derived using four drone flights and augmented by fishing rod and boat surveys at inshore areas of weed growth (potential buoy/drone snag hazard).

Site 3 (Figure 5) comprised a legal enquiry regarding flood hazards and, thus, predicted water volumes in an upland lough in Northern Ireland (details confidential, still subject to enquiry). This example is shown as an area devoid of conventional forensic targets, as a comparator to Site 1, the data being free of submerged objects. It also demonstrates a known limit to sonar and CHIRP - the presence of thick aquatic weed growth in the southern area of the lake, where both devices' acoustic wave reflected from surface mats of pond weed (Bog Pondweed (Potamogeton polygonifolius) and the invasive species of Canadian Pondweed (Elodea canadensis)). 


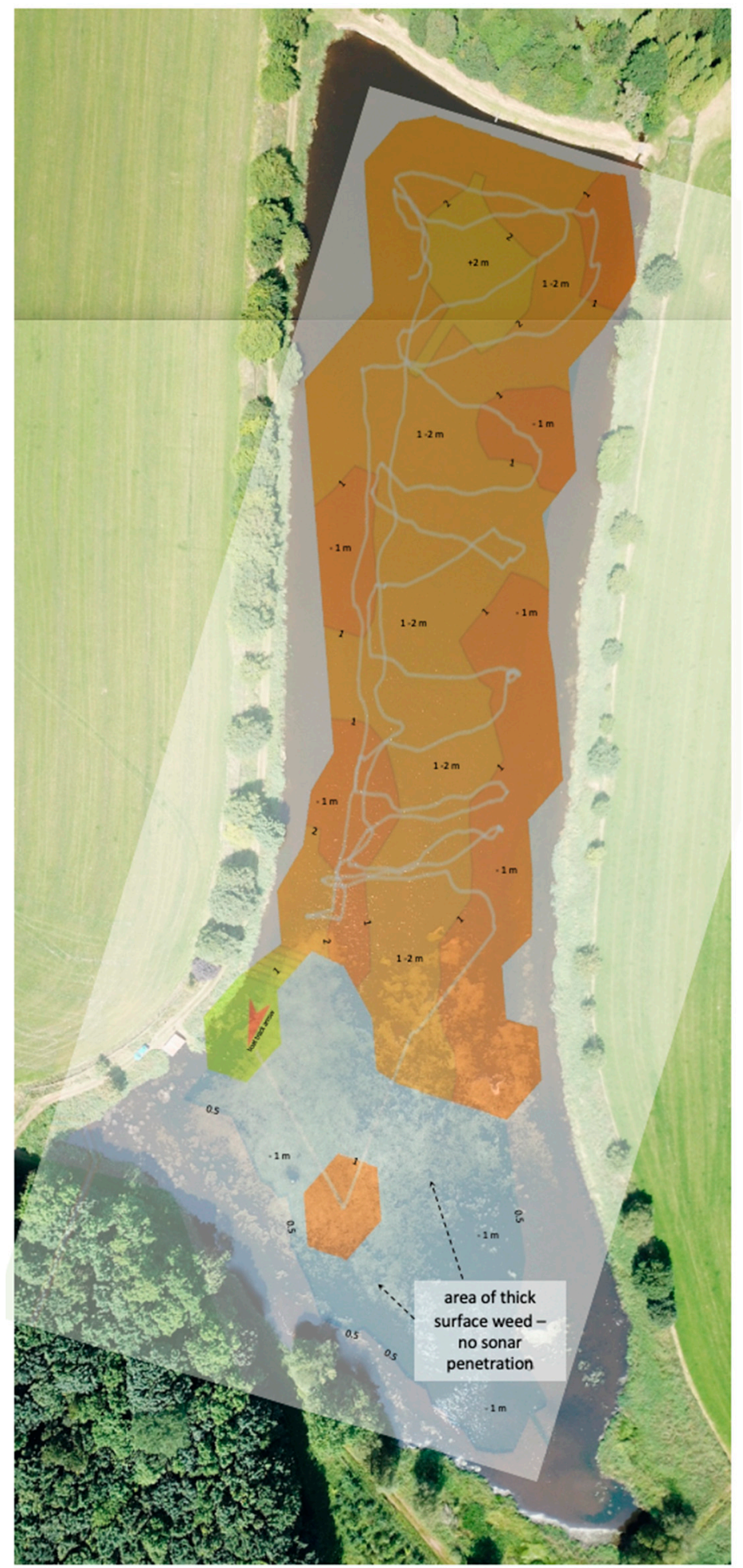

Figure 5. Site 3, where few subaqueous targets occur and weed growth limited sonar deployment by drone or boat due to surface reflections. Flight lines are left on the map, for illustrative purposes.

\section{Validation}

As with all geophysical and remote sensing techniques, the validation of results is essential. For the bathymetric 2D profiling of waterways, the works of Bandini et al. [10] and Giambastiani et al. [11] achieve this with excellent statistical methods and results, which cannot be bettered here. Bandini et al. [10] describe an in depth comparison of 
drone tethered sonar compared to other approaches for mapping bathymetry and also errors associated with the depth measurements from the Deeper Smart Sonar+. In a forensic search of water, this is no different, as geophysical/remote sensing devices are checked against plumb-bob depth measurement. However, this is not ideal, as many search scenarios are in waterways with no obvious firm base, being gradational from water, water suspended sediment, through thixotropic sediment to firm layers: these may be tens of centimeters to a few meters in depth, in which the search target may reside. While this introduces uncertainty in which horizon sonar is reflecting from, this problem of threshold is commonly solved by carrying out freshwater search surveys using WPR (see Ruffell \& Parker [15]. At Site 2, Deeper CHIRP+ $2\left(240 \mathrm{kHz}\right.$, narrow $20^{\circ}$ beam) and WPR $(200 \mathrm{MHz})$ data were collected simultaneously. A comparison between the sonagram and radargram is presented in Figure 6. This example demonstrates the gradational nature of the lake floor being surveyed on the sonar: the WPR is undoubtedly subject to the concept of a dielectric threshold at the $200 \mathrm{MHz}$ frequency used, providing a clear lake floor reflection.

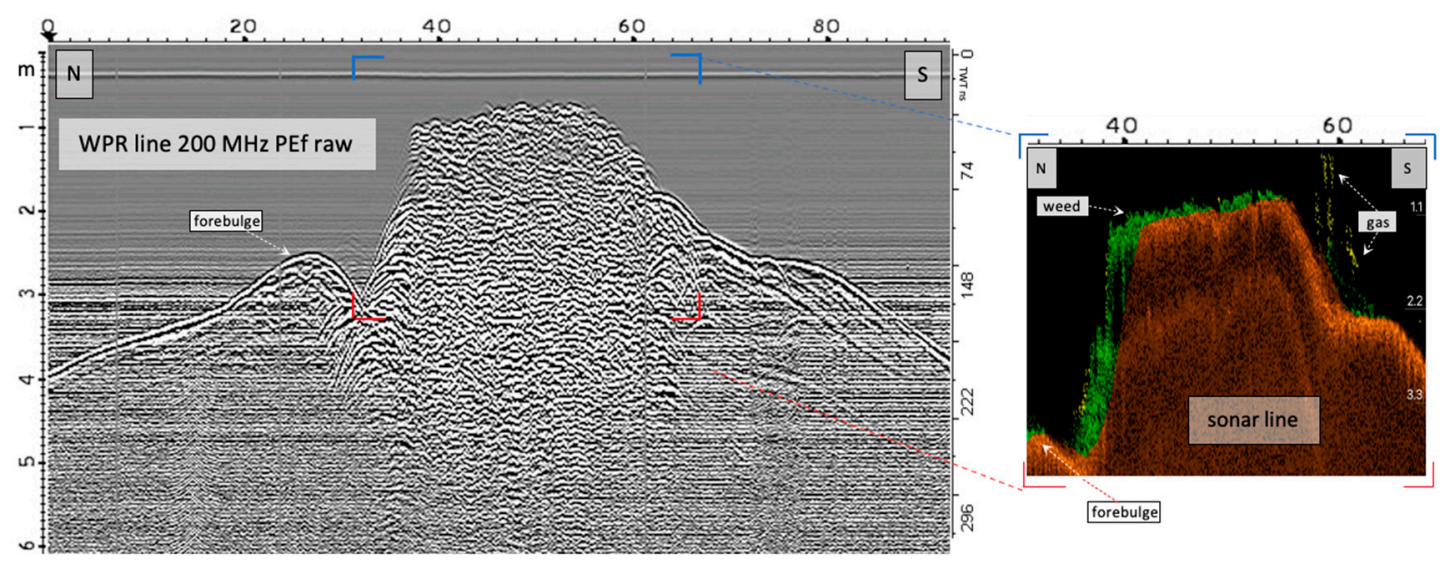

Figure 6. Example of the comparative and conjunctive use of WPR and sonar over Site 2. The radargram (left) depicts an underwater crannog which is comparable with the sonagram (right).

As in terrestrial forensic search, the use of different methods for cross validation is highly recommended, if not always logistically possible or environmentally suitable.

As WPR and sonar data can be gathered simultaneously, either by boat for the radar and Dronar, or both from a boat, it is recommended both are used conjunctively. Ground penetrating radar systems may be deployed from a drone [16]; and, thus, our geoforensic search method of sonar from a drone may also be undertaken simultaneously.

\section{Future Applications and Limitations}

Previous studies present the applications of drone based sonar in hydrological sciences and hydraulic engineering [10] along with estimating reservoir water capacity [11]. In this work, we propose that drone based sonar can provide a rapid, on site assessment of bathymetry, underwater hazards and sediment/vegetation cover for water based forensic searches. With suitable conditions in the absence of contemporary background data, it shows potential as a survey asset, by combining the work of Bandini et al. [10] and Giambastiani et al. [11]. Such a survey is useful for input to a presearch desk top study and on site evaluation of water sunken objects, such as human remains, weapons, drugs, contraband, wreck/crash sites and (as seen above) in forensic engineering. Where the search target may be beneath sediment in water, the use of sub-bottom profilers and/or WPR may be used in combination, or targeted over areas shown from the Dronar. The basis of this work is in gathering data as part of a forensic search for specific items. Like other geophysical techniques, however, Dronar may provide an "easy win" and locate the specific item, or limit the search to a number of targets: current (confidential) work by the authors at homicide search locations suggests that this is possible, validated by us 
successfully scanning a diver in a swimming pool and living volunteer limbs in water storage vessels (rain butts). Limitations to drone acquisition include: adverse weather, such as strong winds and even minor precipitation; waves of more than 5-10 cm height (hindering sonar buoy and thus drone movement); upstanding snagging objects and thick surface aquatic weed growth. A common criticism of drone surveying is battery life (typically 15 to $20 \mathrm{~min}$ ), which we show is of minor concern, given that with numerous batteries and a vehicle/mains/generator charging means, data can be incrementally added as a search progresses. Sonar devices can likewise be rapidly recharged. Above 1 to $2 \mathrm{~km}$ distance from shore or line of sight, drone-based surveys become unsafe and such large water bodies commonly have minor waves, although estuaries are an ideal search location, being sheltered and impossible to survey by ground and water penetrating radar [17] Advances in drone battery life, and the deployment of a quick release mechanism (such as in Bandini et al. [10], with sonar on a 20 to $30 \mathrm{~m}$ tether (to allow operator time for release when landing) and monitoring by an observational drone above may be possible ways to overcome such limitations.

\section{Conclusions}

To facilitate water based forensic searches and reconnaissance surveys, we propose the use of drone based sonar as a cost effective reliable method of bathymetric mapping and feature and hazard identification that can be easily integrated into current practice. This work tested the feasibility of this approach using two different lightweight sonar devices across three study areas. We conclude that commercially available sonar systems tethered to a drone can map bathymetry and identify sunken targets in favorable conditions. Nevertheless, vegetation or high wind conditions could impact the effective implementation of the approach. Dronar can be used for gathering background information of potential study areas, particularly in logistically challenging locations, were boat derived data cannot be collected. Furthermore, drone based sonar can be deployed as an initial step of a search operation in order to provide real time depths and identify possible hazards to boats and divers.

Supplementary Materials: The following are available online at https:/ / zenodo.org/record/5728782, Video S1: Drone Launch MP4, Video S2: Sonar Deployment MP4, Video S3: Drone-Sonar Water Survey MP4, Video S4: Drone-sonar system leaving water survey, Video S5: Summary Drone-Sonar Flight, Video S6: Sonar-Drone Real-Time Imaging MP4, Video S7: Creating Bathymetric Maps from Raw Data in GIS Software.

Author Contributions: Conceptualization, A.R.; methodology, validation, formal analysis, A.R., B.R., A.L., writing original draft, A.R., writing review and editing, B.R. and A.L., funding acquisition, B.R. and A.L. All authors have read and agreed to the published version of the manuscript.

Funding: AL was funded by the Natural Environment Research Council Doctoral Training Programme (NERC-DTP): QUADRAT and the Queen's University Belfast Soulby Research Fund. BR was funded by the Queen's University Belfast Hugh Wisnom Research Fund.

Institutional Review Board Statement: Not applicable.

Informed Consent Statement: Not applicable.

Acknowledgments: A.L. and A.R. are indebted to Rob Storrar (Sheffield Hallam University) and Sai Kelly (SaiKo Productions) for drone pilot work. We are grateful for site permissions from: Queen's University Water Ski Club (Site 1, Lough Henney), especially Barry Rankin; John Erwin (Lough Aghery test site); Dawson Jones, Park Rangers and Leo King (Site 2, Castlewellan Lake, managed by the Department of Agriculture and Rural Affairs); Peter Mackie, County Antrim (Site 3, location anonymised). A previous sonar survey at Site 1 was conducted by Brian Johnstone and Conor Graham (Queen's University Belfast), who are thanked. Equipment was made available by John McNeill, Laganside Tackle, Lisburn. We thank all the fishing enthusiasts, water skiers, paddle boarders, kayakers and wild swimmers for their patience and interest.

Conflicts of Interest: The authors declare no conflict of interest. 


\section{References}

1. Donnelly, L.J.; Harrison, M. Geoforensic search strategy (GSS): Ground searches related to homicide graves, terrorism and serious and organised crime. In A Guide to Forensic Geology; Donnelly, L.J., Pirrie, D., Harrison, M., Ruffell, A., Dawson, L.A., Eds.; Geological Society: London, UK, 2021; pp. 21-49.

2. Somers, M.L.; ARStubbs, A.R. Sidescan sonar. IEE Proc. F Commun. Radar Signal Process. 1984, 131, 243-256. [CrossRef]

3. Becker, R.F. Underwater Forensic Investigation; CRC Press: Roca Baton, FL, USA, 2021; p. 371.

4. Schultz, J.J.; Healy, C.A.; Parker, K.; Lowers, B. Detecting submerged objects: The application of side scan sonar to forensic contexts. Forensic Sci. Int. 2013, 231, 306-316. [CrossRef] [PubMed]

5. Hodges, R.P. Underwater Acoustics: Analysis, Design and Performance Sonar; Wiley: Chichester, UK, 2010; 376p.

6. Healy, C.A.; Schultz, J.J.; Parker, K.; Lowers, B. Detecting submerged bodies: Controlled research using side-scan sonar to detect submerged proxy cadavers. J. Forensic Sci. 2015, 60, 743-752. [CrossRef] [PubMed]

7. Blondel, P. Searching for dead bodies with sonar. In Drowning: Prevention, Rescue, Treatment; Bierens, J.J.L.M., Ed.; Springer: New York, NY, USA, 2014; pp. 1161-1165.

8. Lafferty, B.; Quinn, R.; Breen, C. A side-scan sonar and high resolution CHIRP sub-bottom profile study of the natural and anthropogenic sedimentary record of Lower Lough Erne, northwestern Ireland. J. Archaeol. Sci. 2005, 33, 756-766. [CrossRef]

9. Jackson, D.R.; Baird, A.M.; Crisp, J.J.; Thomson, P.A.G. High-frequency bottom backscatter measurements in shallow water. J. Acoust. Soc. Am. 1986, 80, 1188-1199. [CrossRef]

10. Bandini, F.; Olesen, D.; Jakobsen, J.; Kittel, C.M.M.; Wang, S.; Garcia, M.; Bauer-Gottwein, P. Bathymetry observations of inland water bodies using a tethered sing-beam sonar controlled by an Unmanned Aerial Vehicle. Hydrol. Earth Syst. Sci. 2008, 25, 4549-4565.

11. Giambastiani, Y.; Giustic, R.; Cecchi, S.; Palomba, F.; Manettis, F.; Romanelle, S.; Bottai, L. Volume estimation of lakes and reservoirs based on aquatic drone surveys: The case study of Tuscany, Italy. J. Water Land Dev. 2020, 46, 84-96.

12. Gutowski, M.; Bull, J.; Dix, J.; Henstock, T.; Hogarth, P.; Hiller, T.; Leighton, T.; White, P. Three-dimensional high resolution acoustic imaging of the sub-seabed. J. Appl. Acoust. 2008, 68, 412-421. [CrossRef]

13. Stoelzle, M.; Stein, L. Rainbow color map distorts and misleads research in hydrology-guidance for better visualizations and science communication. Hydrol. Earth Syst. Sci. 2021, 25, 4549-4565. [CrossRef]

14. Ruffell, A.; King, L. Water penetrating radar (WPR) in Archaeology: A Crannog case study. J. Archaeol. Sci. Rep. 2021. in preparation.

15. Ruffell, A.; Parker, R. Water penetrating radar. J. Hydrol. 2021, 597, 126300. [CrossRef]

16. Saponaro, A.; Dipierro, G.; Cannella, E.; Panarese, A.; Galiano, A.M.; Massaro, A. A UAV-GPR fusion approach for the characterisation of a quarry excavation area in Falconara Albanese, Southern Italy. Drones 2021, 5, 40. [CrossRef]

17. Wilson, B.D.; Madsen, J.A. Acoustical Methods for Bottom and Sub-bottom Imaging in Estuaries: Benthic Mapping Project to Identify and Map the Bottom Habitat and Sub-Bottom Sediments of Delaware Bay. Sea Technol. 2006, 47, 43-46. 